\title{
Corpo dramático existencial: atriz e educadora (entre)laçadas
}

\author{
MARIENE HUNDERTMARCK PEROBELLI ${ }^{1}$ \\ IDA MARA FREIRE²
}

\footnotetext{
Professora efetiva do Curso de Teatro da Universidade Federal de Uberlândia, possui especialização em Docência para o ensino superior pela UNISUL (2006) e Comunicação pela UDESC (2009). Doutoranda do Programa de Pós-Graduação em Artes Cênicas da UNIRIO. Tem experiência na área de Artes, com ênfase em Teatro, atuando principalmente nos seguintes temas: teatro, corporalidade, educação, infância e formação de educadores.

2 Professor Associado na Universidade Federal de Santa Catarina, possui formação em Pedagogia e Dança. Pósdoutorado em Tópicos Específicos da Educação (Disability Arts) pela University of Nottingham (2002) e Pós-Doutorado na área de dança na Universitiy of Cape Town (2011-2012). Tem experiência na área de Educação, com ênfase em Educação - Comunicação, atua principalmente no estudo e na pesquisa sobre os temas: alteridade, arte, cegueira, corpo, dança e formação de professores. Autora do blog: www.escrevedance.blogspot.com
} 


\section{- RESUMO}

O presente texto revela uma experiência de entrelaçamento da atriz e da educadora observado no corpo da autora. Tal entrelaçamento é revelado na existência do outro. Esta pesquisa busca compreender as possibilidades de coexistência entre personas que co-habitam um mesmo indivíduo, no caso a própria pesquisadora. É um ensaio fenomenológico dirigido por Maurice Merleau-Ponty em diálogo com Jerzi Grotowski, Eugênio Barba, entre outros... Na tentativa de compreender as relações, singularidades e entrelaçamento entre atriz e educadora, surge a forma do texto dramático. As personagens se encontram em um café, conversam, percebem suas diferenças e semelhanças ao passo em que digerem a fenomenologia e se reconhecem na existência entrelaçada.

\section{PALAVRAS-CHAVE}

Teatro, educação, fenomenologia.

\section{ABSTRACT}

The present text reveals an experience of interaction between the actress and the educator, observed in the body of the author. Such an interlacement is revealed in the existence of others. This research looks to understand the means of coexistence between personas who exist in the same individual, in this case, the investigator herself. It is a phenomenological test directed by Maurice Merleau-Ponty in dialogue with Jerzi Grotowski, Eugênio Barba ... In an attempt to understand relations, singularities and interlacement between actress and educator, is the form of dramatic text. The characters are in a coffee, to talk, percept their differences and similarities while in that digest the phenomenology and recognize the existence interwoven.

\section{KEYWORDS}

Theatre, education, phenomenology.

O texto dramático aqui apresentado é fruto e parte da dissertação de mestrado intitulada $O$ avesso do corpo: uma experiência de reversibilidade entre Teatro e Educação, defendida no Programa de Pós-Graduação em Educação da Universidade Federal de Santa Catarina, em 2009.

Tal pesquisa visava investigar o entrelaçamento do Ser-atriz e o Ser-educadora no corpo da pesquisadora. A questão-problema que norteou a jornada da pesquisa foi: como se afetam as dimensões atriz \& educadora neste corpo em experiência de pesquisa? A expectativa foi gerar impulsos que provoquem deslocamentos. Descobrir pontos de encontro e entrelaçamento dos corpos: atriz e educadora em experiências com o Teatro e a Educação em um ensaio fenomenológico.

No prefácio da Fenomenologia da Percepção, Merleau-Ponty (2006) diz que é em nós mesmos que encontramos a unidade da fenomenologia e seu verdadeiro sentido. Mas é o próprio filósofo quem afirma que a fenomenologia só é acessível a um método fenomenológico. Não se trata de explicar nem de analisar, mas de descrever, pois o mundo está ali antes de qualquer análise que eu possa fazer dele.

Sendo assim, o método da fenomenologia pode ser entendido como empírico no sentido que depende das experiências e reações de cada indivíduo, envolvendo, portanto aspectos culturais, intelectuais e emocionais.

Esta pesquisa pretendeu observar e descrever como acontece o encontro entre o corpo-atriz e o corpo-educadora, as artes cênicas e a educação através de um 
estudo de caso experimental. Para isso utilizamos o método de observação nas abordagens qualitativas, pressupondo um grande envolvimento com a situação estudada, visto que os vividos, o corpo atriz e educadora são o ponto de partida e a própria trajetória da pesquisa. O referencial teórico dialoga com as experiências e vividos.

Diversas experiências entre Teatro e Educação foram vividas, percebidas, refletidas e descritas ao longo da pesquisa. Realizamos oficinas de Teatro com educadores/as da Educação Infantil ao Ensino Médio, desvelando saberes sensíveis intrínsecos à experiência teatral. Descrições de experiências do trabalho da atriz incorporam a pesquisa. Três artistas-educadores são convidados a escreverem juntos um texto sobre suas percepções a partir da pergunta: o que me acontece quando ator/atriz e educador/a se afetam? $\mathrm{Na}$ busca do espelhamento, realizamos uma entrevista com uma atriz-educadora, investigando em seus vividos a relação entre o corpo atriz e educadora.

Mas, ao longo desta pesquisa, atriz e educadora entrelaçaram-se de tal forma, que se tornou quase impossível a percepção de uma e outra como singulares. Porém, para que pudéssemos compreender como se dá o entrelaçamento entre elas, precisávamos distingui-las. Tornou-se necessário perceber suas diferenças, peculiaridades, singularidades. Como separá-las, visto que juntas formam um único Ser que é e está no mundo?

$\mathrm{O}$ contexto da realidade naquele momento mostrava-se confuso. Estavam atriz e educadora tão entrecruzadas que suas singularidades não se tornavam perceptíveis. A pesquisadora, encorajada pela orientação, decide então experienciar o contexto da ficção como possível caminho. A forma encontrada para observá-las uma a uma, surgiu na escritura de um texto dramático, onde atriz e educadora se encontram, conversam, discordam, entram em acordo e se reconhecem. Forma e conteúdo entrelaçados formando um corpo textual. Este texto dramático não teve, portanto, em sua criação, a pretensão de vir à cena. Mas sim, apresenta uma forma possível de fazer, criar e pensar a pesquisa em Artes Cênicas. Foi preciso mais uma vez, arriscar-se. Como a ciência aprovaria um texto dramático em uma dissertação de mestrado?

Assumir os riscos. Realizar e ser a própria experiência, como propõe a fenomenologia. Ela, a fenomenologia, é o lugar de onde falamos e seu método é o que dá suporte a tamanha ruptura textual. Decidir ser-personagens: Atriz; Professora e Garçom.

Atriz e Professora se encontram em um café: La Reversibilité. Ações e falas revelam as singularidades de cada uma. O Garçom apresenta o cardápio e faz sugestões de bebidas e pratos a serem provados e digeridos. Mas estes não são alimentos quaisquer. $\mathrm{O}$ cardápio brinca com os conceitos da fenomenologia que foram trazidos e refletidos ao longo da pesquisa. Atriz e Professora digerem a fenomenologia e a partir dela, se reconhecem e encontram a cisão que não separa: diferenciação de si a si (Atriz; Professora; Garçom): a fissura do Ser.

No momento presente, quebram-se os padrões, sem perder o rigor. lluminamos atriz e educadora neste espaço cênico de pesquisa:

Título:

Encontro no La Reversibilité!

Personagens:

Professora - Mulher. Atrapalhada, mas compenetrada. Discreta. Realista. Intelectual. Roupas clássicas. 
Atriz - Mulher. Expressiva. Observadora. Autêntica. Sonhadora. Artista. Roupas coloridas.

Garçom - Homem. Observador. Discreto. Veste-se de preto e branco.

No espaço, uma pequena mesa redonda com duas cadeiras de madeira. Logo ao fundo um balcão de bar. A professora entra com uma pilha de livros em uma mão e uma pasta cheia de folhas na outra. Ela está um pouco descabelada; com os olhos bem abertos observa o espaço e se encaminha diretamente para a mesa. Senta em uma das cadeiras. Sobre a mesa formam-se duas pilhas: uma de livros e a outra de papéis. Ela olha no relógio. Inspira profundamente. Abre a bolsa (grande). Mexe e remexe em busca de algo. Não encontra. Revira, remexe. Aproxima-se o garçom:

Garçom (Apresenta o cardápio e oferece um olhar misterioso) - Boa tarde. O que a senhora gostaria de ver?

Professora (com a cabeça enterrada na bolsa, levemente irritada) - Não consigo ver!

Garçom - A senhora precisa de alguma ajuda?

Professora - Não, obrigada, quero ver com meus próprios olhos.

Garçom - Vejo que...

Professora (olha subitamente para o Garçom) - Você está vendo?

Garçom - Sim...

Professora (volta para a bolsa) - Onde?

Garçom - Vejo que a...

Professora (tirando a cabeça de dentro da bolsa, dirigindo-se ao garçom) - Não, não me diga!

Garçom - Senhora...

Professora (volta para a bolsa) - Preciso ver por mim mesma.

Garçom - A senhora está...

Professora - São esses meninos que me deixam assim...

Garçom - Um tanto atordoada.

Professora - Assssssim! Achei! Finalmente!

Ergue-se de dentro da bolsa com um estojo pink. Abre, pega os grandes óculos e veste.

Professora - Ah, agora sim... Sim! Eu quero ver! Obrigada.

O garçom entrega-lhe o cardápio. Ela analisa atentamente.

Entra no café a Atriz. Todos os olhos dirigem-se para ela. Ela faz uma pausa dramática. Observa ao redor. Seus olhos encontram a Professora. Ela respira e se encaminha para a mesa.

Atriz - Olá! O que você está vendo?

Professora - Oi! Tudo bem? Estou aqui, analisando as alternativas.

Atriz - E como te parece?

Professora - Hummm... múltiplas escolhas...

Atriz - A fome me atravessa!

Professora - O que a fome te suscita?

Atriz - Vazio. Desejo. Movimento.

(Pausa.) 
Atriz - E a você?

Professora - Se tenho fome e não como, fico muuuuito irritada! Uma fera mesmo, não se aproxime que eu avanço!

(Risos)

Atriz - Mas você ainda não chegou nesse ponto, não?

Professora - Ainda não.

Garçom (aproxima-se) - Nosso maitre, Rubem Alves, sempre diz que é a fome que põe em funcionamento o aparelho pensador.

Atriz e Professora (juntas) - Sinto-me afetada.

Atriz - Estou faminta! Deixe-me ver esse cardápio. (Surrupia outro cardápio das mãos do garçom)

Garçom (lentamente) - Sim, senhora... A verdadeira cozinha é aquela que sabe a arte de produzir a fome...

Atriz - Hummmm!!! Quanta delícia!!! Nem sei por onde começo...

Professora - Podemos chamar algo para entrada...

Atriz - Sim, parece bom.

Garçom - Já que fome é afeto e o pensamento nasce do afeto, nasce da fome, sugiro canapés de affecare. Eles vêm do latim, que quer dizer "ir atrás". Nosso maitre elaborou esse prato especialmente para colocar em movimento a alma em busca do objeto de sua fome.

Atriz (expressiva) - Nossa!!! Parece-me ótimo! Perfeito para o que desejamos, não?

Professora (pensativa) - Sim, perfeito.

Atriz (olhando intrigada para a Professora) - Querida, o que está te afetando?

Professora - Esse prato nunca me foi oferecido na escola...

Atriz - Verdade, na escola jamais comi algo parecido... Mas o pessoal lá do teatro costuma se alimentar diariamente com refeições de affecare. Sabe como é, né, amiga? A gente se alimenta com movimentos em busca de nossos desejos.

Professora - Não compreendo.

Atriz - O vazio, a falta.

Professora - Você preenche o vazio do estômago com refeições de affecare?

Atriz - O vazio do estômago é fácil de preencher. Eu me refiro aos vazios da alma. Às minhas faltas, ausências... Aquilo que me coloca em suspensão...

Professora - Você foi suspensa da escola por conta disso?

Atriz - Não! Ah! Esquece o que eu falei...

Professora - Como assim, esquece? Você é responsável pelas palavras que emite.

Atriz - Mas eu não estou sendo irresponsável, estou?

Professora - Você é assim: solta as coisas no ar, sai de cena e depois deixa a gente se debatendo pra entender.

Atriz - Eu não tenho e nem quero mastigar nada para ninguém!

Professora - Mas nem quero e nem preciso que você mastigue por mim!

Atriz - Você me cansa... Tem a pretensão de entender tudo. Quer saber de tudo, quer ver tudo, quer explicar tudo...

Professora (arregala os olhos) - Eu? Você às vezes me perturba...

Atriz - O que torna possível a experiência criadora é a existência de uma falta ou de uma lacuna a serem preenchidas. Faço de meu trabalho o próprio caminho para 
esse vazio e para determinar minhas indeterminações, levando à expressão o que antes nunca havia sido expresso.

Garçom (interrompendo o clima tenso, fala para a Atriz) - Desculpe a intromissão, mas percebo que nosso drink Espírito Selvagem lhe cairá muito bem com os canapés de affecare.

Professora (sussurra) - Metido, esse garçom, não? Nem pede licença e já vai tomando a palavra...

Atriz (para o Garçom) - Adoro pessoas de atitude!

Garçom (para Atriz) - Este drink fortalece o sujeito que não diz "eu penso", e sim "eu quero", "eu posso", mas que não saberia como concretizar isto que ele quer e pode senão querendo e podendo.

Atriz - Parece-me perfeito.

Garçom (para Professora) - E você, o que deseja para acompanhar?

Professora (de canto de olho para a Atriz, provocativa) - Você aceita minha companhia? Ou está muito cansada de mim?

Atriz - Querida, não vamos permitir que nossas diferenças criem desafetos. Cada qual é o que é.

Professora - Bem, como eu... não sou tão ousada, aceito esse (apontando no cardápio) Atitude Natural para começar.

Garçom - Providenciarei.

Professora - Desculpe, eu me exaltei. Ando muito estressada. Crianças hiperativas, adolescentes sem limites, mal educados, escola sem estrutura, colegas de trabalho desmotivados... Isso tudo me tira do eixo...

Atriz - Tudo bem. Eu tenho muito o que aprender com você. Essa sua paciência infinita de repetir incansáveis vezes aquilo que as pessoas nem sempre estão interessadas em saber... Eu sou assim, digo o que quero dizer, faço o que sinto vontade de fazer. Talvez soe como provocação, mas no fundo acho que é apenas uma brincadeira, talvez um jogo...

Professora (sorrindo) - Você e seus jogos... teatrais?

Atriz (sorrindo) - Você e suas explicações... didáticas?

(As duas riem juntas.)

Professora - Mas sabe que esses nossos encontros no La Reversibilité tem me afetado?

Atriz - Mesmo?

Professora - Sim. Cada dia falo menos. Semana passada dei uma aula sem emitir sequer uma explicação.

Atriz - Nossa! O que está te acontecendo?

Professora - Sim, tenho elaborado cada vez planos mais arriscados.

O Garçom entra e serve os canapés de affecare, o drink Espírito Selvagem para a Atriz e o Atitude Natural para a Professora. Elas comem enquanto prosseguem com a conversa.

Atriz - Hummm... Esses canapés são deliciosos! Sou capaz de voar em busca do objeto de minha fome...

Professora - Não tenho emitido conceitos, mas venho oferecendo estímulos que provocam deslocamentos. 
Atriz - Muito interessante isso! guntas.

Professora - Tenho experimentado descrever as atividades em forma de per-

Atriz - Para isto que deveriam existir as escolas, não para ensinar as respostas, mas para ensinar as perguntas.

Professora - Quem me ensinou a perguntar?

Atriz - Amo os porquês! Creio que talvez sejam a mola propulsora que me ejetam nesse mundo.

Professora - Questionar é arriscado. Então me entrego à exposição com tudo o que ela tem de vulnerável e arriscada.

Atriz - Prova esse Espírito Selvagem, vejo que você vai gostar.

Professora - Sim, eu quero. (Bebe.) Eu posso! Posso agir, realizar uma experiência e ser a própria experiência, não?

Atriz - O que você sente?

Professora - Começo a sentir uma... falta?

Atriz - Falta de que?

Professora - Não sei... um... vazio?

Atriz - São os primeiros sinais.

Professora - Começo a retornar. Preciso de um tempo...

A Professora silencia por alguns instantes.

A Atriz a observa com olhar de encantamento. Ouve-se uma música que toca ao fundo no café, enquanto o Garçom serve Batatas Husserlianas.

\author{
Love-Devotion \\ Feeling-Emotion \\ Don't be afraid to be weak \\ Don't be too proud to be strong \\ Just look into your heart my friend \\ That will be the return to yourself \\ The return to innocence. \\ If you want, then start to laugh \\ If you must, then start to cry \\ Be yourself don't hide \\ Just believe in destiny. \\ Don't care what people say \\ Just follow your own way \\ Don't give up and loose the chance \\ To return to innocence \\ That's not the beginning of the end \\ That's the return to yourself \\ The return to innocence.
}

(Enigma, 1994)

Professora - Sinto que, pela primeira vez começo a retornar às coisas mesmas...

Garçom (para a Professora) - Creio que já podemos suspender seu drink "Atitude Natural", não?

Professora - Sim. Parece não me cair bem... 
O Garçom tem em mãos espátulas em forma de parênteses, com as quais retira o copo de "Atitude Natural" da mesa. Professora e Atriz se entreolham com ares de estranhamento.

Atriz - Essas Batatas Husserlianas estão me fazendo retornar ao irrefletido, ao mundo vivido...

Professora - Parece que agora posso abrir-me ao mundo e aos outros.

Garçom - Percebi que vocês aprovaram as Batatas Husserlianas, trouxe mais uma porção.

Atriz - Grata.

Professora (comendo) - Agora percebo que a verdade não habita o "homem interior", ou antes, não há homem interior, o homem está no mundo e é no mundo que ele se conhece.

Atriz - Sim, reconheço-me nisso.

Professora - Qual o meu lugar, como professora, neste mundo?

Atriz - A escola?

Professora - Pois é... Eu não me reconheço na escola. É paradoxal. Sou professora, meu lugar de ação deveria ser a escola, mas sinto repulsa. É como se eu não coubesse na escola, compreende?

Atriz - Sim.

Professora - Sinto-me presa.

Atriz - Presa a quê?

Professora - Presa ao sistema, à forma, ao currículo, ao tempo, ao espaço, à mesmice, à repetição, à falta de alegria e motivação... Falta-me o ar!

Atriz - O que te faz feliz como professora?

Professora - As descobertas. Os olhos que brilham, sabe? Quando percebo que o outro desperta. Algo lhe acontece. Ele se remexe. Então se move em busca de algo que lhe causa interesse. Poder provocar e acompanhar esse processo. Nossa, isso me deixa completamente feliz!

Atriz - Sei, sinto algo semelhante quando atuo. Percebo que as pessoas estão comigo. Sinto que seus olhos me tocam, ouço sua respiração, sinto que os tenho em minhas mãos. Quando somos juntos, apenas um, e capazes de suspender o tempo e o espaço. Isso é alucinante!

Professora - Esses momentos fazem valer a existência!

Atriz - Sinto-me leve, expandida... Eu, os outros e o mundo somos um...

Professora - Sabe, até mesmo aquele que me faz uma provocação me deixa feliz. Mas não falo da provocação de birra, e sim da provocação que me move, me transforma em interrogação e aí suspendo tudo o que antes acreditava saber. Os conceitos caem ao chão. O outro me provoca a retornar, abandonar as certezas e recomeçar.

Atriz - E então recomeçamos juntos... Amo esse jogo! Quando o outro ator me surpreende e faz o que jamais pensaria em fazer. Vejo o que não podia antes ver. Perco o chão, o risco é total. O instante presente passa a ser uma incógnita. Nada mais é o que era antes. Sou capaz de dizer o indizível! (Solta uma gargalhada). Sendo assim, desse ponto em diante tudo é possível. Então não há espaço para pensamentos e devaneios, apenas o improviso e a ação. É algo que vem com o exercício, ninguém ensina a ninguém. O teatro me ensinou que aprender é coisa de fazer.

Professora - Sinto muita falta disso na escola. Fala-se muito. Você estava certa 
quando disse que eu quero saber de tudo, entender tudo. Parece que há uma pressão para que tenhamos respostas prontas e imediatas para todas as perguntas e ocasiões.

Atriz - Foi assim que nos ensinaram...

Professora - Pode existir uma professora sem certezas?

Atriz - Será?

Professora - Apesar de muitas pesquisas contemporâneas proporem o contrário, a escola ainda é o lugar das respostas certas.

Atriz - Não há lugar para o erro.

Professora - Os erros são punidos. Na prática, não temos o direito de aprender com nossos próprios erros.

Atriz - Eu também sou muito exigente comigo mesma. Creio que todos nós queremos acertar. Mas em alguns momentos, só errando conseguimos ver o caminho certo. Mas, para permitir-se errar, é preciso não temer o ridículo.

Professora - Talvez hoje não haja tempo para errar. Quando o aluno erra, corrigimos. Como não há tempo para que ele encontre por si o caminho certo, mostramos para ele e seguimos com a "matéria", pois o tempo corre e precisamos dar conta dos conteúdos curriculares programados para o ano letivo. (Pausa.) Muitas vezes o aluno ainda nem viu aquilo que mostramos, mas temos que passar logo para o tópico seguinte, pois os outros precisam prosseguir.

Atriz - Errar não deveria fazer parte da experiência?

Garçom (trazendo guardanapos) - A possibilidade de que algo nos aconteça requer um gesto de interrupção.

Atriz e professora ficam imóveis, com os guardanapos paralisados na boca enquanto o Garçom prossegue seu discurso.

Garçom - Jorge Larrosa esteve aqui outro dia e disse que para que a experiência nos aconteça, é preciso parar para pensar, parar para olhar, parar para escutar, pensar mais devagar, olhar mais devagar, e escutar mais devagar; parar para sentir, sentir mais devagar, demorar-se nos detalhes, suspender a opinião, suspender o juízo, suspender a vontade, suspender o automatismo da ação, cultivar a atenção e a delicadeza, abrir os olhos e os ouvidos, falar sobre o que nos acontece, aprender a lentidão, escutar aos outros, cultivar a arte do encontro, calar muito, ter paciência e dar-se tempo e espaço.

Atriz e Professora voltam a se mexer lentamente, como em câmera lenta. Comem e bebem.

Professora (fala lentamente) - Já não sei se alcanço aquilo a que me proponho. Atriz - (fala lentamente) - Já não me defino mais por meus sucessos e poderes.

O Garçom recolhe os pratos e copos.

Professora - Percebo que sou...

O garçom passa a mão por trás da Atriz para recolher guardanapos sujos, esta 
se inclina para trás na cadeira, levando as mãos à cabeça. A Professora faz sinal com os braços para avisar a Atriz e com isso bate na pilha de livros, que vai ao chão. A Atriz bate no Garçom, que derruba a bandeja com pratos e copos. A Atriz vai ajudar a recolher, bate na mesa e derruba as pastas e folhas.

Os três paralisam os movimentos, criando uma imagem congelada.

Silêncio.

Pausa.

Juntos e lentamente retomam os movimentos e se entreolham.

Garçom - Algo nos passou.

Atriz (calmamente) - Estamos tombados.

Professora (tranquilamente) - Derrubados.

Garçom - Parece que somos um território de passagem...

Atriz (lentamente reorganizando os objetos no espaço) - Sinto agora que não há separação entre sujeito e objeto.

Garçom - Percebo em vocês abertura para desfrutarem de nosso prato principal: Sequência de Ponty.

Professora - Sugestivo.

O Garçom sai com os objetos recolhidos na bandeja. Atriz e Professora voltam a sentar.

Atriz - Retorno... o que é ser atriz?

Professora - Você está perguntando isso para mim?

Atriz - Para mim... Buscar em mim a manifestação do humano no mundo. Penetrar em mim para encontrar a humanidade, o ponto que toca os demais seres. Sair de mim, para encontrar o outro e então encontrar a mim mesma. Abertura, mergulho, entrega, desvelamento, criação, brincadeira, jogo, espontaneidade, trabalho, disciplina...

Professora - Você gosta dessa exposição?

Atriz - Gosto da exposição do Ser. Poder trazer à visibilidade os aspectos invisíveis. O que é muito diferente da exposição que a mídia faz com os atores, criando celebridades.

O Garçom retorna.

Garçom - Aqui estão os bolinhos de Ponty, que dão abertura à sequência.

Atriz - Obrigada.

Elas comem e prosseguem dialogando.

Professora - Sim. Há certos atores que vejo em cena e nada me tocam, não posso ver nada além de sua aparência. O rosto, o corpo e suas virtuosidades. Onde moram suas fraquezas? Onde se esconde a "feiúra"? O que há para além da visível beleza? A serviço de que está a sua arte?

Atriz - Conheço muitos artistas que caem nessa cilada. O que para mim é uma cilada, pois é um mundo que não passa de ilusão. 
Professora - A questão é: qual é o seu processo? Você é fiel a ele ou luta contra ele?

Atriz - A essência é amiga da simplicidade. Mas esse mundo está tão poluído de conceitos, sentidos e juízos que nos perdemos das essências e muitas vezes nem somos capazes de perceber que não estamos vivendo nossa existência.

Professora - O que seria viver sua existência?

Atriz - Vivo minha existência quando estou em harmonia com minha essência. Logo sei que sou fiel ao meu processo quando amo verdadeiramente e me entrego ao que faço. (Retira um caderno de anotações da bolsa e abre.) Outro dia mesmo retornei à Grotowski e anotei aqui: Se o processo está ligado à essência, somos então levados ao que Grotowski chama de "corpo-e-essência" e assim somos capazes de captar o próprio processo.

Professora - Às vezes olho para você e percebo que seu corpo não está resistente, é quase transparente.

Atriz - Sim, quando vivo minha existência em essência, percebo que sou leve, iluminada e evidente.

Professora - Estes bolinhos me fazem digerir uma questão... O processo a que se refere Grotowski poderia ser a existência que provamos em Merleau-Ponty?

Atriz - Boa pergunta! Recordo de uma antiga história que conta Grotowski no artigo O Performer: "Nós somos dois. O pássaro que bica e o pássaro que observa. Um vai morrer, um vai viver." O problema é que estamos ocupados com o bicar, bêbados com a vida dentro do tempo e então nos esquecemos de manter viva a parte, em nós, que observa.

Professora - Parece então que há o perigo de existir somente dentro do tempo, e em nenhum momento fora do tempo.

Atriz - Sentir-se visto pela outra parte de si mesmo, a que está como que fora do tempo, nos dá outra dimensão. É isso o que sinto quando atuo. É como se existisse um Eu - Eu.

Professora - Esse segundo tu seria quase virtual?

Atriz - Sim. Não é em nós o olhar dos outros e nem o julgamento. É como um olhar imóvel. Uma presença silenciosa. Como o Sol que ilumina as coisas.

Professora - Talvez o processo de cada um a que se refere Grotowski somente possa se completar no contexto dessa presença imóvel.

Atriz - Livre de pensamentos, julgamentos e conceitos. Colocamo-nos em suspensão.

Professora - Mas esse Eu - Eu significa ser dividido em dois?

Atriz - De forma alguma. A dupla Eu - Eu não está separada, mas plena e única.

Garçom - É chegada a hora de vocês provarem o Ser Bruto. (Serve-as).

Professora (provando) - Hummmm... sinto que sou um ser de indivisão... Já não estou submetida à separação entre sujeito e objeto, alma e corpo, consciência e mundo, percepção e pensamento.

Atriz (provando) - Sinto a nervura secreta que sustenta e conserva unidas as partes, dando-me uma estrutura que mantém diferenciados e inseparáveis o direito e o avesso: é o invisível que faz ver porque sustenta por dentro o visível; o indizível que faz dizer porque sustenta por dentro o dizível; o impensável que faz pensar porque sustenta por dentro o pensável.

Professora - Percebo que é por um "sistema de equivalências" diferenciado e 
diferenciador que há o mundo.

Atriz - Parece que estamos desatando os liames costumeiros entre as coisas.

Professora - Esse tal "Ser Bruto" cai muito bem com o drink "Espírito Selvagem", prove!

Atriz - Hummmmm... Sim, eles parecem abraçados, entrelaçados...

Professora - Esse entrelaçamento faz com que o invisível permita o trabalho de criação do visível; o indizível, o do dizível; o impensável o do pensável... para então fazer surgir o jamais visto, jamais dito, jamais pensado!

Atriz - A obra! Isto é a obra de arte! É dessa exibição que falo, que nada mais é que o desvelamento do Ser.

Garçom - Dando sequência, entrelaçamos "Ser Bruto" ao molho de "Espírito Selvagem", temos então, a "Polpa Carnal do Mundo".

Professora - Desculpe, mas somos vegetarianas.

Garçom - Mas essa é uma carne que todos somos capazes de provar, visto que não é uma carne qualquer.

Atriz - Mas então o que é essa tal polpa carnal do mundo?

Garçom - Carne de nosso corpo e carne das coisas.

Atriz e Professora - Éca!

Garçom - Não falo de carne relacionada a esse corpo como máquina de músculos e nervos ligados por relações de causalidade e observável do exterior. Mas é interioridade que se exterioriza, é e faz sentido.

Atriz - Que lindo!

Garçom - Se as coisas do mundo e nós nos comunicamos, não é porque elas agiram sobre nossos órgãos dos sentidos e sobre nosso sistema nervoso, nem porque nosso entendimento as transformaria em ideias e conceitos, mas porque elas e nós participamos da mesma Carne.

Professora - Eu quero provar!

Atriz - Você me convenceu...

(As duas comem).

Garçom (dando uma risadinha) - Mesmo os vegetarianos não escapam da "Carne do Mundo".

Atriz - "Carne do Mundo"?

Garçom - O que é visível por si mesmo, dizível por si mesmo, pensável por si mesmo.

Professora (mastigando) - Essa tal "Carne do Mundo" não é um ser pleno maciço, e sim um ser pleno poroso.

Atriz (mastigando) - Sim, é habitado por um oco pelo qual um positivo contém nele mesmo o negativo que aspira por ser, uma falta no próprio Ser.

Garçom - A "Carne do Mundo" é o "Quiasma" ou o entrecruzamento do visível e do invisível, do dizível e do indizível, do pensável e do impensável, cuja diferenciação, comunicação e reversibilidade se fazem por si mesmas como estofo do mundo.

Professora - Veja! Uma fissura que se preenche ao cavar-se e que se cava ao preencher-se.

Atriz - Não é, pois, uma presença plena, mas presença habitada por uma ausência que não cessa de aspirar pelo preenchimento e que, a cada plenitude, remete a um vazio sem o qual não poderia vir a ser.

Professora - Agora compreendo o vazio, a falta de que você falava no início do 
nosso encontro, e que te leva a ser atriz. Parece que seu corpo vive uma osmose com seu processo.

Atriz - Já não sei se me encontro na personagem ou na não-personagem...

Professora - Será que posso me expor e ser verdadeiramente eu em sala de aula?

Atriz - Minha essência se revela no espaço cênico ou no espaço cotidiano?

Professora - Creio que posso ser eu em sala de aula. Revelar minha maneira de ser, por mais diferente que seja da maioria dos demais professores. Mas há aspectos que não posso revelar no espaço docente. Trago à visibilidade aquilo que é aceito nas convenções da escola. E ainda assim, provoco estranhamentos... Aquilo que torno visível é sustentado pelo invisível. As palavras que engulo, por não poder expressá-las (o indizível), sustenta o dizível. O ser que digo não caber na escola - o impensável -sustenta o ser que se adapta à escola - o pensável.

Atriz - Qual a atração que o palco exerce sobre o meu Ser e sobre tantos outros Seres?

Professora - Por que as pessoas vão ao teatro?

Atriz - Talvez o espaço do palco, por ser o espaço da ficção, do virtual, uma abertura para outras dimensões, nos permita o desvelamento, trazer à visibilidade o invisível. Sinto-me plena em cena por isso, posso revelar o que no dia-a-dia é invisível, indizível, impensável...

Professora - Talvez por isso as pessoas vão ao teatro: para ver o invisível, para escutar o indizível e pensar o impensável.

Atriz - A obra de arte se revela por mim ou no espectador?

Professora - A obra de arte existe entre mim e você.

Atriz - O espetáculo teatral não é; ele está em constante movimento. Ele se refaz a cada apresentação. Mesmo que o texto, os atores, a direção e mesmo que o público fosse composto hoje pelas mesmas pessoas que assistiram à apresentação de ontem; a obra não será a mesma. Há sempre o novo por vir, pois o eu e os vocês de hoje já não são os mesmo de ontem...

Professora - Quando você entra em cena, você preenche ou esvazia o palco?

Atriz - Quando você entra em sala de aula, você preenche ou esvazia os conteúdos?

Garçom - Observem este queijo suíço.

Atriz e Professora olham atentamente.

Garçom - Quanto mais queijo, mais furo.

Professora - Mas quanto mais furo, menos queijo!

Garçom - Sim. Logo, quanto mais queijo, menos queijo.

Atriz - E quanto menos queijo, mais queijo...

Professora - Que loucura!

Atriz - Estou confusa... sinto-me enlaçada pelo mundo e as coisas do mundo...

Professora - Sinto-me entrecruzada... visível e invisível, dizível e indizível, pensável e impensável...

Atriz - Compartilho da mesma sensação...

Atriz e Professora se entreolham reconhecendo-se uma na outra.

Voz em off:

Vejo a Atriz em cena falando tudo isso. Vejo as pausas e o desejo de ser compreendida. O que acontece em você acontece no outro à medida que flui e percorre 
os seus poros. Parece um ensaio tudo isso. Aquele momento anterior à cena e quando nos perguntamos o que estamos fazendo ali, prestes a encantar os outros todos. Mais fácil ficar em casa, tranqüila, tranqüila. Mas seria possível?

Fim.

Pulsa uma questão: Como seria o encontro entre Atriz e Professora no teatro pós-dramático?

\section{Referências}

ALVES, Rubem. Ao professor, com o meu carinho. Campinas: Verus, 2004.

. Um céu numa flor silvestre: a beleza em todas as coisas. Campinas: Verus, 2005.

BARBA, Eugênio. Além das Ilhas Flutuantes. Tradução de: Luis Otávio Burnier. Campinas: Hucitec, 1991.

CHAUÍ, Marilena. Convite à filosofia. São Paulo: Ática, 2006.

Merleau-Ponty: obra fecunda. Disponível em: http://revistacult.uol.com.br/website Acesso em: 4 mar. 2009.

FERNANDES, Ciane. Escrevendançando: teoria e prática na pesquisa em Artes Cênicas. In: BIÃO, Armindo e LEMOS, André. Temas em contemporaneidade, imaginário e teatralidade. São Paulo: Annablume, 2000.

Corpo em movimento: o sistema Laban/Bartenieff na formação e pesquisa em artes cênicas. São Paulo: Annablume, 2006.

GROTOWSKI, Jersy. Em busca de um teatro pobre. Rio de Janeiro: Civilização Brasileira, 1992.

El Performer. In: Mascara, México: Escenologia, ano 3, n. 11-12, 1993.

O Teatro Laboratório de Jerzy Grotowski 1959 - 1969: textos e materiais de Jerzy Grotowski e Ludwik Flazen com um escrito de Eugenio Barba. São Paulo: Perspectiva, 2001.

HEIDEGGER, Martin. La esencia del habla. In: De camino AL habla. Barcelona: Ediciones Del Serbal, 1987.

LARROSA, Jorge. Notas sobre a experiência e o saber de experiência. Revista Brasileira de Educação. p. 20-28, jan/abr. 2002.

Pedagogia profana: danças piruetas e mascaradas. Tradução de: Alfredo Veiga-Neto. Belo Horizonte: Autêntica, 2006.

MERLEAU-PONTY, Maurice. Fenomenologia da percepção. Tradução de: Carlos Alberto Ribeiro de Moura. São Paulo: Martins Fontes, 2006. 
O olho e o espírito. Tradução de: Paulo Neves e Maria E. Glavão Gomes Pereira. São Paulo: Cosac\& Naify, 2004.

. O visível e o invisível. Tradução de: José Artur Gianotti e Armando Mora d'Oliveira. São Paulo: Perspectiva, 2007.

MINAYO, Maria Cecília de Souza.(org.) Pesquisa social: teoria, método e criatividade. Petrópolis: Vozes, 1994.

REZENDE, A. M. Concepção fenomenológica da educação. São Paulo: Cortez, 1990.

SOKOLOWSKI, Robert. Introdução à fenomenologia. Tradução de: Alfredo de Oliveira Moraes. São Paulo: Edições Loyola, 2004. 